\title{
NEW PARTRIDGE DICTIONARY OF SLANG AND UNCONVENTIONAL ENGLISH
}

\author{
ROBERT CASS KELLER
}

The following account has been adapted from the Dec 242005 Guardian Unlimited review of Tom Dalzell and Terry Victor's two-volume, 2216-page work, available for $\$ 210$ (£ 120).

Geezer[s], laydeez, check this! It may sound like a load of abba-dabba, or ackamaracka and bafflegab to you, like someone's been on the old Bahama hooter [marijuana cigarette], but listen up - this King Farouk [book] is one daddy-come-to-church [an unusual event]!

If you've noodles [brains] you'll already know that it was one of lexicography's poster boys, Eric Partridge, who compiled the King James version of English-language slang dictionaries in his Dictionary of Slang and Unconventional English, published in various editions from 1937 to 1984, but there's no way Partridge is any longer going to grip your shit [satisfy your needs] so Tom Dalzell and Terry Victor have produced a two-volume jazzed-up version. Badda-bing!

Most slang dictionaries are no better than momgrams [postcards sent home at start of Marine Corps basic training] or a rub of the brush [bar drinks made out of leftovers], put together by shmegegges [incompetents] looking to make some moola. The New Partridge Dictionary, on the other hand, is the wee babes [expression of appreciation]. At over 2000 pages it's mondo and pretty authoritative, including entries not only from the United Kingdom and America but also from Australia, New Zealand, India and the Caribbean. Who's the daddy [in charge]?

The average Guardianista [liberal politically-correct person] may find some of the sex talk grody to the max, since much of it is dicky-dunking [sex from a male perspective] and it's like barf me out! Jane, please not in front of the men!

So is the book offensive? How high is a Chinaman [is the Pope Catholic]? Slang has always been language with additood, and Dalzell and Victor go out of their way to include offensive language about everything and toward just about everyone, from esthole [EST supporter] to 'Whitney dressed as Britney' [an older person garbed in younger fashion].

Some readers may get their Alans [knickers] in a twist over all the drug references: indeed, there's so much talk about drugs in the book it makes you feel like you're on A, B, C, D and E [LSD, benzedrine, cocaine, dilaudid, Ecstasy] just reading it. But of course the book is research rather than reportage or recommendation and you'd have to be one hell of a drug monkey to have tried everything from edelweiss [Dutch marijuana] to zonked [GHB].

To read both volumes you'd have to be at it from arsehole to breakfast time [all the time], but of course no one would want to try and swallow the whole enchilada because it'd give you baboon butt [sore buttocks from motorcycle riding], eyes like piss-holes in the snow, and send you across the bridge to Dartmouth or East Ham [mental institutions]. Harpic [injecting a drug slowly]!

Anyhoo, nobody wants to sound like they're an eggsucker [sycophant], or like they're trying to accrue chocolate [act deferentially to a policeman] by offering gee [praise], so let me put in my $\$ 0.02$ worth. There is not much Hinglish, there's no cross-referencing, so it's impossible to tell 
what's ajax [near] to anything else. The book includes too many golden oldies, and some of them pretty Jimmy Nail [stale]. Like Partridge before them, Dalzell and Victor go full guns on all things military and anything to do with Amerikkka and I'm like, whatever [so what?].

But back in the teapot, dormouse [be quiet, to a child]! You might think that compiling a dictionary of slang is as easy as kiss my arse. Ex-as-like [not!]. This is no California pimping [laid-back pimping]. Dalzell and Victor are eager-beavers and their method seems to be a combination of careful research, earwigging [eavesdropping], presumably in places like East Jesus, Arkansas [Podunk], and by guess and by God [casual form of navigation].

The New Partridge Dictionary may not be the sort of thing you'd enjoy with an Al Pacino [cappuccino] and your kidney punch [lunch] of Eskimo salad [moss from a caribou stomach] al desko [at work]. It's a book and a half, so just eat what you can and can what you can't [conservation motto]. End of [enough said]. 